\title{
Assessing the progress and gaps in strategic health
}

\section{purchasing in Kenya [version 1; peer review: 1 approved with}

\section{reservations]}

\author{
Jacob Kazungu(iD), Evelyn Kabia(D1), Kenneth Munge (iD)2, Edwine Barasa1,3 \\ ${ }^{1}$ Health Economics Research Unit, KEMRI Wellcome Trust Research programme, Nairobi, Kenya, 43640, Kenya \\ ${ }^{2}$ World Bank, Kenya Country Office, Nairobi, Kenya \\ ${ }^{3}$ Center for Tropical Medicine and Global Health, Nuffield Department of Medicine, University of Oxford, Oxford, UK
}

V1 First published: 13 Apr 2021, 6:81

https://doi.org/10.12688/wellcomeopenres.16606.1

Latest published: 13 Apr 2021, 6:81

https://doi.org/10.12688/wellcomeopenres.16606.1

\section{Abstract}

Background: Kenya has committed to achieve universal health coverage ( $\mathrm{UHC})$ and prioritised purchasing reforms. Existing evidence indicates that purchasing can be leveraged to achieve health system objectives when done strategically. However, no single study has collated evidence on the progress and bottlenecks on strategic health purchasing (SHP) in Kenya to inform requisite SHP reforms in moving towards UHC. Against this backdrop, we assessed the progress and gaps in SHP in Kenya.

Methods: We used a cross-sectional qualitative study design and collected data using document reviews, key informant interviews, and a stakeholder engagement workshop focussing on the three main purchasers in Kenya: the National Hospital Insurance Fund (NHIF), county departments of health $(\mathrm{CDOH})$ and the Ministry of Health (purchaser for vertical programmes). Data was analysed following a framework analysis approach.

Results: Kenya is making progress towards developing, implementing and institutionalising SHP practices that should lead to the attainment of health system goals. Progress has been made in 1) strengthening the process of defining a health benefits package available for the population, 2) engaging in selective contracting and integrated care contracting, 3) implementing multiple provider payment mechanisms, 4) designing legal and regulatory frameworks that provide direction for purchasing, and 5) increasingly utilising information systems. However, several gaps remain. First, there remain inadequate linkages between $\mathrm{MOH}$ policies and the NHIF that can facilitate adequate stewardship/oversight. Second, the purchasers lack adequate capacity to ensure quality assurance and enforce contracts. Third, provider payment methods (PPM) remain poorly designed, implemented, and are not adequately linked to health system goals. Finally, purchasers have weak or unclearly defined communications

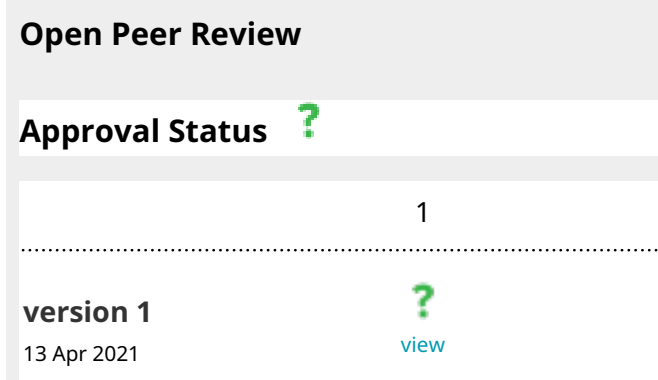

1. Brendan Kwesiga (iD), World Health

Organization, Nairobi, Kenya

Any reports and responses or comments on the article can be found at the end of the article. 
strategies to patients and providers.

Conclusions: Although Kenya is making progress in SHP, key gaps

remain. Consequently, there is a need to implement reforms that will

align the purchasers' actions and decisions to the ideals of strategic

health purchasing.

Keywords

Strategic purchasing, Purchasing, Universal Health Coverage, Kenya

Corresponding author: Jacob Kazungu (kjacob@kemri-wellcome.org)

Author roles: Kazungu J: Data Curation, Formal Analysis, Investigation, Methodology, Writing - Original Draft Preparation, Writing Review \& Editing; Kabia E: Formal Analysis, Methodology, Writing - Review \& Editing; Munge K: Conceptualization, Funding Acquisition, Methodology, Writing - Review \& Editing; Barasa E: Conceptualization, Formal Analysis, Methodology, Supervision, Writing - Review \& Editing

Competing interests: No competing interests were disclosed.

Grant information: This work was supported by the Strategic Purchasing Africa Resource Centre (SPARC). JK and EK are supported by a Wellcome Trust Masters Fellowship grant number $(212347,212489)$ and EB is supported by a Wellcome Trust core award (092654). The funders and the World Bank had no role in study design, data collection and analysis, decision to publish, or preparation of the manuscript. The views expressed in the papers are for the authors and not for the organizations they represent.

The funders had no role in study design, data collection and analysis, decision to publish, or preparation of the manuscript.

Copyright: ( 2021 Kazungu J et al. This is an open access article distributed under the terms of the Creative Commons Attribution License, which permits unrestricted use, distribution, and reproduction in any medium, provided the original work is properly cited.

How to cite this article: Kazungu J, Kabia E, Munge $\mathrm{K}$ and Barasa E. Assessing the progress and gaps in strategic health purchasing in Kenya [version 1; peer review: 1 approved with reservations] Wellcome Open Research 2021, 6:81

https://doi.org/10.12688/wellcomeopenres.16606.1

First published: 13 Apr 2021, 6:81 https://doi.org/10.12688/wellcomeopenres.16606.1 


\section{Introduction}

Universal health coverage (UHC) is a global health agenda that countries have committed to achieve by $2030^{1}$. UHC requires the whole population to have access to good quality preventative, promotive, curative and rehabilitative services relative to need while protecting them from experiencing any financial hardship as a result ${ }^{2,3}$. Consequently, countries, including Kenya, are increasingly reforming their health systems in moving towards $\mathrm{UHC}^{4}$.

Kenya has committed to achieve UHC and prioritised purchasing reforms ${ }^{5}$. Purchasing refers to the transfer of pooled resources to healthcare providers to provide a defined set of services to the population ${ }^{6,7}$. Existing evidence indicates that purchasing can be the critical cause of inefficiencies and a barrier to ensuring the population can equitably access good quality services (if any at all) but can be used as a lever to achieving health system objectives ${ }^{2}$. Purchasing involves three decisions: 1) what to buy - the set of services or benefits package to be purchased, 2) whom to buy from - the set of healthcare providers to be selected to offer the defined set of services, and 3) how to buy -the provider payment methods and contractual arrangements ${ }^{8}$.

As opposed to passive purchasing - using the previous budget or simply paying bills when presented - countries are adopting strategic health purchasing (SHP) as a reform to move them closer to achieving $\mathrm{UHC}^{7,8}$. Strategic purchasing requires a continuous pursuit for better ways to implement the three purchasing decisions in a way that promotes health system performance.

Public sector purchasing in Kenya is conducted by three main purchasers including the National Hospital Insurance Fund
(NHIF), the national ministry of health $(\mathrm{MOH})$ and the county departments of health $(\mathrm{CDOH})$ across 47 semi-autonomous counties (Table 1). The NHIF contracts with public and private providers and uses various provider payment mechanisms. For instance, NHIF uses 1) capitation for outpatient services where providers are reimbursed different rates depending on both their facility level (primary or secondary or tertiary) and the scheme a member belongs (national or civil servants), 2) casebased payments for renal dialysis services, kidney transplant, free maternity program, oncology treatment, surgical services, and rehabilitation services and 3) fee-for-service for radiological, dental, optical services, inpatient and outpatient care for enhanced scheme members?. The national MOH owns tertiary hospitals and pays through global budgets whereas the $\mathrm{CDOH}$ owns both primary and secondary public health facilities and pays using salaries to healthcare workers, line-item budgets and supply of commodities.

No single study has collated evidence on the progress and bottlenecks on strategic purchasing (SHP) in Kenya to inform requisite SHP reforms in moving towards UHC. Consequently, this study describes the progress made on SHP and the gaps hindering progress in SHP in Kenya to also act as a baseline for future monitoring.

\section{Methods}

Study setting

Kenya is a lower-middle-income country (LMIC) with a governance structure comprising a central government and 47 semi-autonomous county governments that enjoy devolved fiscal, political and administrative authority ${ }^{10,11}$. Kenya's health system's performance is lower than expected when compared against historical trends and its peers in areas such as equitable access to key services (such as reproductive, maternal,

\section{Table 1. List of purchasers and whom they purchase from in Kenya.}

\begin{tabular}{|c|c|c|c|}
\hline Purchasers & $\begin{array}{l}\text { Who they purchase } \\
\text { from }\end{array}$ & What they purchase & How they purchase \\
\hline $\begin{array}{l}\text { National Government/ } \\
\text { Ministry of Health (MOH) }\end{array}$ & $\begin{array}{l}\text { National Referral } \\
\text { hospitals }\end{array}$ & Essential package for health & Global Budgets \\
\hline $\begin{array}{l}\text { County departments of health } \\
(\mathrm{CDOH} ; n=47)\end{array}$ & County public facilities & Essential package for health & $\begin{array}{l}\text { Inputs (e.g. salaries, fuel, human resources) } \\
\text { are paid for on a line-item basis within } \\
\text { programme budgets }\end{array}$ \\
\hline $\begin{array}{l}\text { National Hospital Insurance } \\
\text { Fund (NHIF) }\end{array}$ & $\begin{array}{l}\text { Public and private } \\
\text { facilities }\end{array}$ & $\begin{array}{l}\text { Outpatient and inpatient } \\
\text { services based on the benefits } \\
\text { package for the scheme }\end{array}$ & $\begin{array}{l}\text { Capitation for outpatient, case based group } \\
\text { payments (e.g. for day surgeries or outpatient } \\
\text { renal dialysis), fee for service (e.g. for } \\
\text { diagnostic procedures) }\end{array}$ \\
\hline Private health insurers & $\begin{array}{l}\text { Private, and } \\
\text { international health } \\
\text { providers }\end{array}$ & $\begin{array}{l}\text { Outpatient and inpatient } \\
\text { services based on package } \\
\text { paid by each member }\end{array}$ & Fee for service, on a monthly basis \\
\hline $\begin{array}{l}\text { Community-based health } \\
\text { insurers (CBHI) }\end{array}$ & $\begin{array}{l}\text { Low-cost public and } \\
\text { faith-based providers }\end{array}$ & $\begin{array}{l}\text { Outpatient and inpatient } \\
\text { services based on package } \\
\text { paid by each member }\end{array}$ & Fee for service, on a monthly basis \\
\hline
\end{tabular}


new-born, child and adolescent health and immunisation), quality of care (such as effective coverage), and financial protection (such as catastrophic health expenditure) ${ }^{12-14}$.

The health sector is managed at the national and county government levels; the national government is in charge of policy and regulatory roles and management of the national referral hospitals whereas county governments are responsible for health service delivery and ownership of public primary and secondary facilities.

Like many other LMICs, Kenya's total health expenditure (THE) is characterised by large proportions of out-of-pocket (OOP) payments (39.6\% in 2016) and donor funds (23.4\% in $2016)^{15}$. Nearly $20 \%$ of the population in Kenya are covered by some form of health insurance with $89 \%$ of these covered by the NHIF ${ }^{16}$.

\section{Study design and data collection}

We used a cross-sectional qualitative study design, employing a framework analysis approach, to assess the progress and gaps in SHP in Kenya. Three approaches were used to collect data: 1) document reviews (conducted in December 2019), 2) key informant interviews (conducted in November to December 2019), and 3) a stakeholder engagement workshop (conducted in January 2020). The consolidated criteria for reporting qualitative research (COREQ) checklist was used ${ }^{17}$.

Document review. We searched, identified and reviewed documents on 1) previous assessments of healthcare purchasing in Kenya, and 2) health policies, roadmaps, strategic plans, and reports from $\mathrm{MOH}$ reforms task forces such as the health financing reforms expert panel (HEFREP). These documents were identified from 1) simple web searches in Google, 2) a search in PubMed, 3) references of the obtained documents, 4) the $\mathrm{MOH}$ and NHIF websites, and 5) grey literature. Web and PubMed searches included search terms such as "Healthcare Purchasing" OR "Strategic Purchasing" AND "Kenya" and was essential in retrieving peer-reviewed literature.

Key informant interviews (KIIs). Using a semi-structured interview guide ${ }^{18}$ developed from the study's conceptual framework (detailed below), we conducted five out of eight possible key informant interviews (KIIs) with purposefully selected participants based on their roles in organisations and/or in the $\mathrm{MOH}$ working on strategic health purchasing or related health financing activities) from the national ministry of health and other partners working on health financing and/or strategic health purchasing in Kenya. A list of organisations/partners working on health financing in Kenya was drawn and the number of potential respondents determined following the structure of the organisation/partner and previous engagements (Table 2). Potential study participants were approached via email and then by telephone to notify them about the study and request their participation. Approval for participants' participation in the interviews was first sought from relevant organisational heads where applicable. The interviews were conducted in November to December 2019 by JK and EK in the respondents' offices. Before starting the interviews, respondents were presented with information regarding the study objectives, why they were selected, that their participation was voluntary and provided written informed consent. The interview questions focussed on the SHP areas where Kenya is making progress and where challenges exist across the conceptual framework's domains.

Workshop. The findings from the document review and key informant interviews were mapped onto a progress matrix informed by the conceptual framework for the study. The progress matrix presents in tabular form key purchasing functions as well as key steps that should be taken to move towards the most optimal arrangements for those functions (Table 3).

\section{Table 2. Number of key informant interviews (KII) participants by organisation.}

\begin{tabular}{|l|c|c|}
\hline Organisation & $\begin{array}{c}\text { Number of } \\
\text { respondents } \\
\text { targeted }\end{array}$ & $\begin{array}{c}\text { Number of } \\
\text { respondents } \\
\text { interviewed }\end{array}$ \\
\hline Ministry of Health $(\mathrm{MOH})$ & 2 & 1 \\
\hline Council of Governors & 1 & 0 \\
\hline National Hospital Insurance Fund (NHIF) & 1 & 0 \\
\hline Clinton Health Access Initiative (CHAI) - Kenya & 1 & 1 \\
\hline AMREF Health Africa & 1 & 1 \\
\hline ThinkWell & 1 & 1 \\
\hline World health organization $(\mathrm{WHO})$ & 1 & 1 \\
\hline Total & $\mathbf{8}$ & $\mathbf{5}$ \\
\hline
\end{tabular}




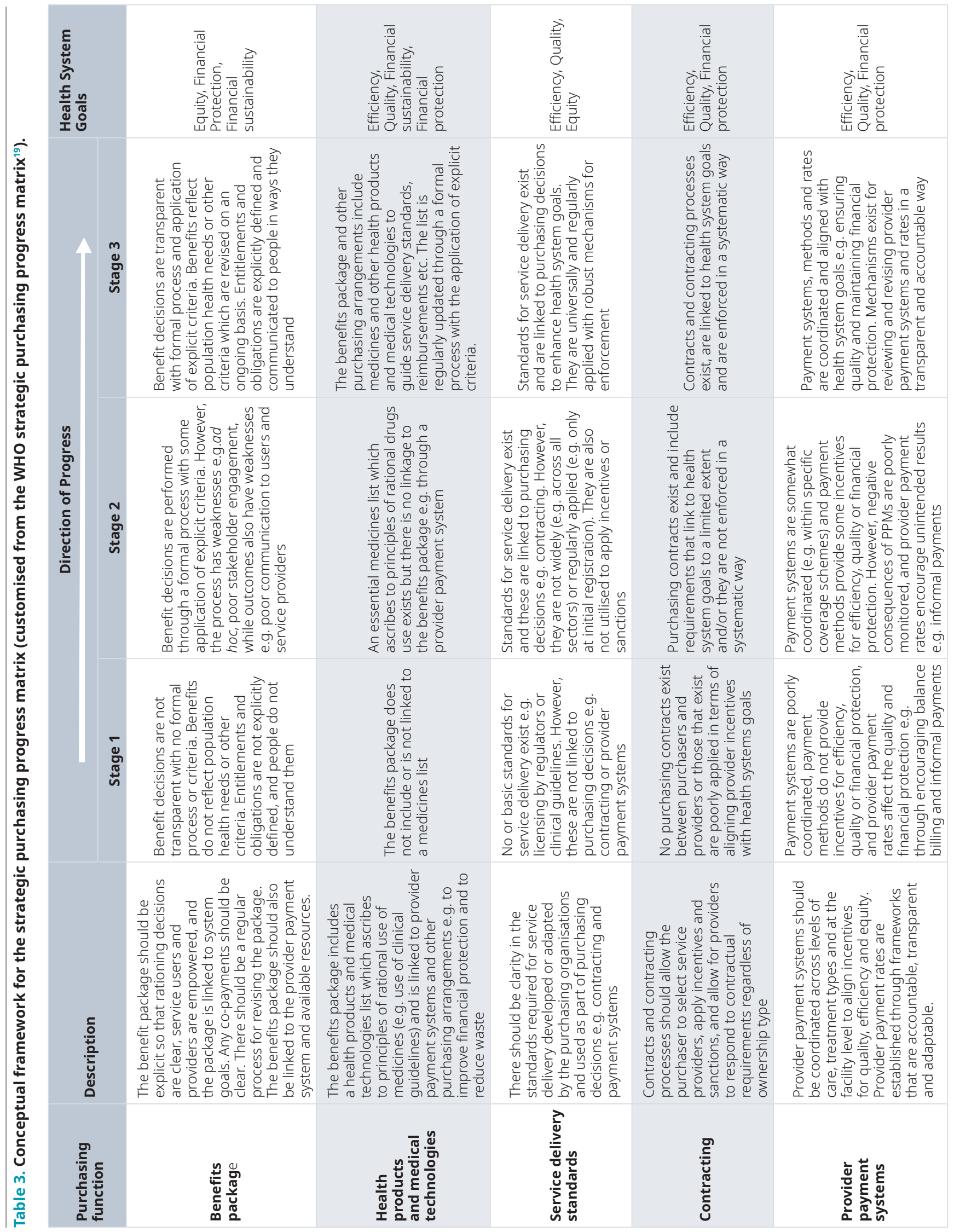




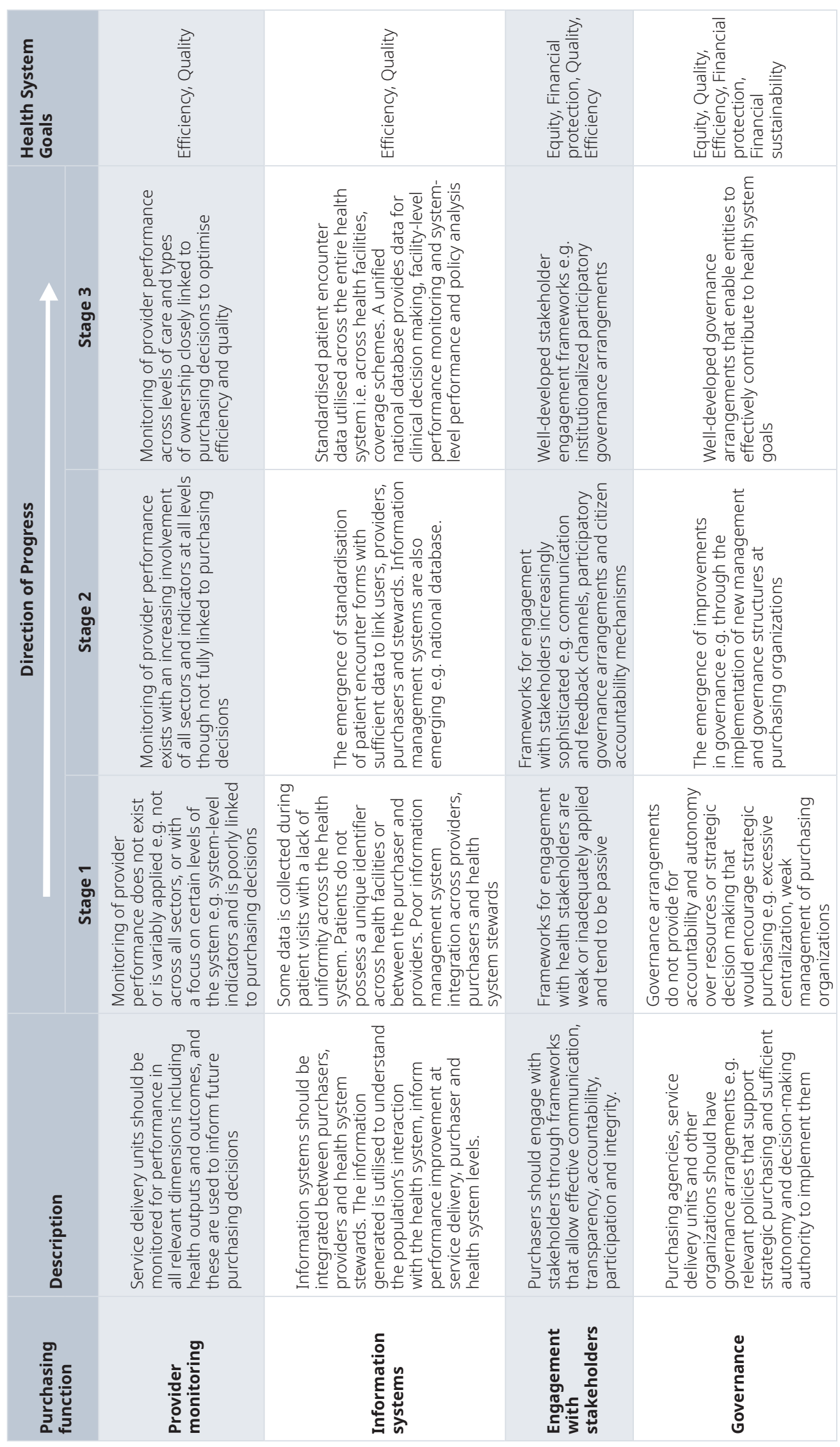


We conducted a deliberative workshop in January 2020 focussing on the progress matrix to validate our findings and identify other areas where purchasers were making progress and/or there remained some gaps. Participants at the workshop were purposefully selected from organisations working on health financing including the $\mathrm{MOH}$, county departments of health and development partners. A total of 27 key participants from the $\mathrm{MOH}$ (5), county governments (4), the NHIF (2), World Health Organization (WHO) (2), ThinkWell (2), Options Kenya (1), the Kenya Medical Association (1), Kenyatta University (1), University of Nairobi (1), Strathmore University (1), the Programme for Appropriate Health Technology (2), Health NGOs Network (1) and Amref Health Africa (2) attended the workshop.

\section{Conceptual framework}

This study was guided by the strategic health purchasing (SHP) progress matrix developed by the Strategic Purchasing Africa Resource Centre (SPARC) ${ }^{20}$ which has similarities to the SHP framework for policymakers and practitioners developed by the Health Finance and Governance (HFG) ${ }^{21}$ and WHO's Health Financing Progress Matrix ${ }^{22}$. Table 3 summarises the conceptual framework and the key steps for making progress towards strategic purchasing in Kenya.

The framework comprises of three main categories: 1) governance arrangements, 2) purchasing functions and 3) other capacities. Governance arrangements focus on the 1) mandate and autonomy of the purchaser with regards to, for instance, decisions/functions the purchaser can carry out; 2) legal or regulatory frameworks - comprising of the laws and regulations available to govern the operations of the purchaser; and 3) governance structures that direct the day-to-day management of the purchaser and both the oversight and internal accountability lines of the purchaser.

Purchasing functions detail the key action areas that a purchaser should decide on including the set of service entitlements (benefits package) that the citizens/members will benefit, the set of providers the purchaser can buy from and the payment methods used to reimburse the providers. Other capacities in the framework relate to how the purchaser communicates with stakeholders and the use of information systems to improve service delivery and the relational aspects of provider contracts.

In this study, we focussed on the three purchasers in the public sector in Kenya: the National Hospital Insurance Fund (NHIF), the Ministry of Health (purchase for vertical programmes), and the county departments of health $(\mathrm{CDOH})$. The three were selected because they are the purchasers with the greatest influence on Kenya's health system and whose reforms can easily be leveraged towards achieving UHC.

\section{Data analysis}

We adopted the framework analysis approach ${ }^{23}$ to analyse the gathered data from KIIs and document reviews. Detailed notes indicating the feedback and comments from the workshop were used to further identify the areas where progress was made and where gaps remain - notes can be accessed here ${ }^{20}$. Two researchers (JK and EK) independently coded the data based on the conceptual framework ${ }^{24,25}$. Discussions with $\mathrm{EB}$ and $\mathrm{KM}$ helped build where variations were observed. The coded data were then interpreted and mapped onto the progress matrix to provide an indication of the stage of progress of the specific domain. The coding of the data was conducted in Word for Microsoft 365 and the mapping onto the progress matrix in Excel for Microsoft 365.

\section{Ethics statement}

We received ethical approval from the Kenya Medical Research Institute (KEMRI) scientific and ethics review unit (SERU) under SERU number SSC 2795. Additionally, the study was permitted by the National Commission for Science, Technology and Innovation (NACOSTI) as well as the Council of Governors. We also engaged relevant organisational heads to discuss the study prior to seeking consent from and interviewing their staff. We obtained written informed consents from all participants who agreed to participate in the study.

\section{Results}

Progress and remaining challenges in strategic health purchasing across key purchasing functions in Kenya

\section{Benefits package}

A continuous pursuit for an explicitly designed benefits package that reflects the health and needs of the population is crucial for making progress in strategic health purchasing in any health system. To this end, Kenya has made progress on strengthening the process of defining a health benefits package that reflects the health needs of the population. Specifically, the MOH's established a health benefits package advisory panel (HBAP) in recognition of the need for an evidence-informed, inclusive and transparent process using explicit criteria, to propose an essential benefit package for UHC for Kenya. The HBAP proposed an essential benefits package that has since informed pilots of health system reforms and may be used for planned expansions of coverage ${ }^{26}$. The National Medicines and Therapeutics Committee (NMTC) has updated the Kenya Essential Medicines And Supplies List (2019) to expand the available medicines list by 419 to $1,072^{27}$. The KEML is intended to complement the essential benefits package. The KEML review was based on nine key selection criteria, including relevance, safety, comparative efficacy, quality, performance and comparative cost-benefit.

However, two key gaps still exist in the benefits package development process. First, the benefits package development process is yet to be institutionalized. The HBAP's term expired in June 2020 while that of the NMTC is poorly defined. Second, the benefits package development process remains fragmented with all three purchasers offering multiple benefit packages that are not harmonized. For instance, the NHIF still uses multiple fragmented benefit packages across the over 70 different schemes it runs. These benefit packages have also not been developed using explicit criteria, and their development has not been transparent and inclusive. 


\section{Whom to buy from}

Purchasers are required to actively identify and contract with a set of providers based on explicit criteria that meet strategic purchasing goals such as the comprehensiveness and quality of services offered, and their geographical location.

Several advancements have been made. First, the NHIF engages in selective contracting (primarily among private providers). The utilisation of selective contracting by NHIF and $\mathrm{CDOH}$ indicates some progress in strategic purchasing as it promotes health system goals including equity in geographical access to providers and services, quality of services delivered, and efficiency. Second, one $\mathrm{CDOH}$ (Kisumu county) has started piloting the contracting of primary care networks aiming to contract a group of facilities (given a single contract) comprising of a sub-county hospital, all public health centres and dispensaries as a bid to enhance efficiency in contracting and service delivery through adherence to, for instance, appropriate referral channels.

Several challenges that hinder provider identification and contracting persist. First, despite the NHIF engaging in selective contracting mainly with private providers, the $\mathrm{MOH}$ and $\mathrm{CDOH}$ performs little if any selective contracting. Second, the NHIF's processes are hindered by the limited choice in areas where certain providers, usually public, are the only option. Third, the NHIF, as a state-owned agency, cannot easily reject a public health facility. The identification and selection function is poorly defined in the $\mathrm{CDOH}$ and $\mathrm{MOH}$, in part because they own and operate many of the facilities from which they purchase health services. This, therefore, may hinder action against poor performing facilities and does not guarantee a citizen's access to service entitlements. Fourth, all three purchasers demonstrate gaps in monitoring and enforcing contractual terms. For instance, although NHIF is required to conduct periodic monitoring of facilities to ensure adherence to contractual agreement, there is a lack of adequate capacity to implement this role. The $\mathrm{MOH}$ and CDOH's monitoring activities are also limited to sporadic inspections for compliance with licensing requirements and routine work supervision. Progress to institutionalize accreditation, quality assurance and inspection as part of monitoring has been slow.

\section{Provider payment systems}

Provider payment mechanisms are crucial for aligning healthcare provider behaviour with health system goals. Adequately designed provider payment mechanisms can incentivize providers to offer high-quality services, efficiently and equitably. In moving towards these, all three key purchasers have primarily incorporated a mix of provider payment mechanisms (Table 1). For instance, the NHIF pays providers on a capitation basis for outpatient services but also uses fee for service for diagnostic services. The MOH uses global budgets for the vertical programmes and the national referral hospitals that it manages whereas $\mathrm{CDOH}$ uses a line-item budget for commodities and salaries, as well as a fee for service for counties with their universal health coverage plans e.g. Makueni.

However, several gaps remain. First, although a range of provider payment systems is in use by the three purchasers and especially by the NHIF, existing evidence shows that they are either poorly designed, poorly implemented, do not protect against fraud/corruption and/or are not adequately linked to health system goals. For instance, the NHIF's implementation of capitation for outpatient services has experienced challenges including misunderstanding by providers $^{28}$, lack of rate negotiation and revision ${ }^{28}$, and inadequate mechanisms to guard against adverse consequences such as fraud by providers ${ }^{28}$. The $\mathrm{MOH}$ and $\mathrm{CDOH}$ mainly utilize line item budgets even where budgets are programme based, budget format would not permit the use of global budgets.

Second, we found that purchasers (particularly NHIF) have multiple payment mechanisms that are incoherent across different schemes. For instance, for normal delivery for members in public facilities, the NHIF pays KES 10,000 (USD 100) under the general scheme but pays KES 5,000 (USD 50) under the free maternity scheme. This fragmentation does not promote strategic purchasing as it sends different signals to providers that may hinder equity, efficiency and quality of services. Additionally, payment rates are often inadequate and not informed by evidence e.g. costing. Furthermore, across the three purchasers, existing evidence shows that payments are often unpredictable both in amounts and timeliness ${ }^{28}$ which influences provider behaviour and impacts patients access to services.

\section{Governance arrangements}

Governments are required to establish clear frameworks and accountability mechanisms that guide purchasers' actions ${ }^{8}$. The three purchasers have legal frameworks that guide their operation. For instance, the NHIF is regulated by the National Hospital Insurance Fund Act of $1998^{29}$, and the $\mathrm{MOH}$ and $\mathrm{CDOH}$ by the Health Act of 2017and the Public Finance Management Act of 2012. The CDOH may also be regulated by various subnational level acts such as the County Finance Act.

There has been some progress in addressing gaps in the legal and regulatory environment in a bid to improve strategic purchasing practices. For instance, the HEFREP review included a review of the governance structure of NHIF that will explicitly restructure around members and "employer enrolment, beneficiary relations, provider empanelment, contracting, claims management" and adequate oversight from the $\mathrm{MOH}^{5}$. Additionally, proposed amendments to the NHIF Act currently being considered by parliament require regular reporting on health service purchasing performance by the NHIF to the $\mathrm{MOH}$ and the public.

Besides, some counties have passed county-level public financial management legislation to enhance the financial autonomy of public health facilities which improves the functioning of provider payment methods. The $\mathrm{MOH}$ and county governments have prioritised greater intergovernmental collaborations to achieve coherence in the legal and policy frameworks. For instance, the $\mathrm{MOH}$ is supporting counties to generate local solutions (such as local legislation) to PFM bottlenecks.

Despite these advancements, three key challenges remain. First, we found the government, through the $\mathrm{MOH}$, lacking effective 
oversight strategies specifically on the NHIF even though the NHIF's CEO and board of directors are required to report to the cabinet secretary of health. Further, the $\mathrm{MOH}$ has insufficient oversight of the semi-autonomous or vertical programmes that purchase healthcare services on its behalf. Second, there remain inadequate linkages between $\mathrm{MOH}$ policies and the NHIF that can facilitate adequate stewardship/oversight. For instance, $\mathrm{MOH}$ policies do not yet identify the NHIF as a strategic purchaser of healthcare services in Kenya and do not clearly define the role of NHIF. Third, the accountability of the NHIF to the government appears to be biased towards financial accountability and neglecting operational accountability. Therefore, while the government has clear mechanisms to hold the NHIF accountable for financial issues, they do not have clear mechanisms to hold the NHIF accountable to strategic purchasing objectives.

\section{Information systems}

Information systems are a key building block in all efficient healthcare systems. Purchasers are required to develop, manage and use information systems to purchase strategically. Additionally, providers are required to communicate with stakeholders to share information, raise awareness about, inter alia, the benefits package. To this end, there is a continued emphasis on the utilisation of health information systems across purchasers in Kenya. For instance, the Kenya Health Information System (KHIS) is now widely used by the public sector with a continued improvement in data quality. Additionally, the recent HEFREP review recommended revamping the NHIF's information systems such as the claims management system into a fully automated and paperless claims process with well-developed information technology (IT) infrastructure to enable offline interaction, smooth user experience, verification, pre-authorization and vetting systems.

However, Kenya still lacks a unified national database that can permit clinical decision-making, facility performance monitoring and an examination of hospital performance at a system level. Besides, all three key purchasers have weak or unclearly defined communication strategies useful for patients to understand their service entitlements and feedback mechanisms for users to share experiences and raise complaints. For instance, while NHIF advertising on Supa Cover (one of the NHIF schemes) has increased, there remain weaknesses in communication to the user (e.g. about entitlements, responsibilities, and key processes) with the modes used (such as television and social media) favouring the rich and people in urban settings. Additionally, the $\mathrm{MOH}$ and $\mathrm{CDOH}$ have fragmented communication strategies with key stakeholders where for example the key health programmes such as community health services and key policy documents such as the Kenya health sector strategic plan have separate and incoherent communication strategies.

\section{Discussion}

This study aimed to assess the progress and gaps in strategic health purchasing using SPARC's progress matrix framework across three main purchasers in Kenya: the NHIF, the MOH and
$\mathrm{CDOH}$. We utilise a progress matrix approach ${ }^{20}$ to assess the progress and gaps in strategic health purchasing in Kenya which is similar to the WHO's health financing progress matrix ${ }^{22}$. The current assessment demonstrates that progress is being made on moving towards more strategic health purchasing practices (what to buy, from whom, and how) that should lead to the attainment of health system goals.

On what to buy (benefit package), the assessment highlights the initiative by the government to introduce and institutionalize an evidence-based benefit package development process. A strategic purchaser is required to adequately identify and define the set of services or interventions to purchase for the population ${ }^{8}$. Having an evidence-based health benefits package is the first step into making the NHIF a strategic purchaser, however, this needs to be implemented to remove the fragmentation in benefit package across the 74 NHIF schemes ${ }^{5}$.

On whom to buy from, as purchasers are required to adequately identify a set of providers to purchase services from, the NHIF's engagement with providers in selective contracting is a positive step into promoting provider competition and the delivery of good quality and timely services at the least $\cos ^{30}$. Evidence from other settings has shown that selective contracting can be leveraged as a mechanism to control healthcare $\operatorname{costs}^{31,32}$. Additionally, although only piloted in one county (Kisumu), the assessment highlighted a change in contracting from contracting individual providers to contracting a network of providers. This is in line with the HEFREP recommendation on NHIF contracting reforms to introduce an integrated care contracting ${ }^{5}$. Integrated care contracting enhances the integration of healthcare service provision whilst reducing inefficiencies in contracting resulting from contracting multiple providers individually.

On how to buy, our findings show that purchasers utilise multiple provider payment mechanisms, however, these are not aligned to incentivize providers to enhance efficiency and/or quality of services. Existing evidence from a purchasing study in Kenya revealed that the differences (such as predictability and sufficiency) in the multiple funding flows to public health facilities lead to undesired provider behaviour such as inequitable prioritisation of resources and services in favour of patients from schemes with higher payment rates ${ }^{33}$. Similar findings have been reported from studies in Nigeria ${ }^{34}$. It is essential to consider the economic signals that different provider payment mechanisms have on provider behaviour to both develop and implement coherent provider payment mechanisms that elicit the required incentives for meeting the health system goals ${ }^{35-37}$.

Other than the above three strategic purchasing decision areas, the role of governance and information systems in aligning systems in moving towards UHC cannot be overemphasised. On governance arrangements, while the primary finding is that robust legal and regulatory frameworks that provide direction for purchasing exist on paper, there is poor implementation and oversight or stewardship from the government. Well developed 
and implemented regulatory frameworks are levers for governments and purchasers to affect the equity, quality, effectiveness, quantity and safety of healthcare services across the health system thus improving the performance of health systems ${ }^{38,39}$.

Lastly, on health information systems, the assessment showed an increased shift to the utilisation of information systems such as the Kenya Health Information System. Information systems are crucial to providing the evidence required to monitor the performance of both purchasers and providers and as a lever for an active engagement of the purchaser with the providers, citizens and the government ${ }^{8}$. Reid et al. refers to information and communication systems as the "backbone of health care delivery" for all functioning health systems ${ }^{40}$ and thus the need for investment into the infrastructure and capacity of information systems.

Our findings should be interpreted considering the following limitations. The document review was not as systematic as would be expected in systematic reviews rather was used to supplement web searched from the key purchasers' websites. Consequently, we don't present a PRISMA flow diagram in this manuscript ${ }^{41}$. Additionally, whereas our findings focus on the three key purchasers in Kenya, other purchasers such as private health insurance and community-based health insurance exist but were not assessed. However, their contribution to overall coverage is low ${ }^{42}$.

However, based on these findings, we make several recommendations. First, there is a need to implement the benefits package developed by the health benefits advisory panel, and to institutionalize health technology assessment as an evidencebased approach to healthcare priority setting. There is also a need to accompany these reforms by the harmonization of benefit packages while removing the fragmentation in the current duplicated and incoherent benefit packages across the three purchasers. Additionally, adopted benefit packages should reflect current and projected resources available. Second, there is a need for the $\mathrm{MOH}$ to embrace the stewardship role and provide oversight to the NHIF and the vertical programmes. Good enforcement of the established laws and policies is essential in improving health system performance ${ }^{39}$. A specific improvement would be a clear articulation of strategic purchasing objectives and accountability requirements between the $\mathrm{MOH}$ and the NHIF. Third, all purchasers should have explicit requirements for engaging with providers to ensure that health facilities improve on the quality, equity, and efficiency of the services they deliver while enhancing provider accountability and that their selection and contracting is pro-equity. Fourth, purchasers should tailor their provider payment mechanisms to ensure that they are coherent, elicit the required provider behaviour and promote health system goals. For instance, provider payment rates should be based on costing evidence. Fifth, purchasers should enhance the adoption of information systems by making investments and building capacity for information systems such as the Kenya Health information system (KHIS). Sixth, purchasers should explicitly communicate the service entitlements to citizens and action on their complaints and feedback. Poor communication hampers public accountability and the responsiveness of the purchasers to citizens needs and requirements. Effective communication of purchasers builds awareness of service entitlements and trust among citizens which promotes strategic purchasing ${ }^{39}$.

\section{Conclusion}

In conclusion, although purchasers in Kenya have made progress in, inter alia, establishing structures such as legal frameworks, contractual agreements with providers, provider payment mechanisms and the use of information systems that are in line with the ideals of strategic purchasing actions, the design and implementation of these structures remain poor and fragmented. Given the role that the three purchasers in Kenya play and the government prioritisation of strategic purchasing as a lever for moving towards UHC, there is a need for reforms that align the purchasers' actions to the ideal strategic purchasing actions.

\section{Data availability}

\section{Underlying data}

Documents reviewed in this analysis are publicly available. Transcripts from the interviews are not publicly available due to them containing personal identifying information that could compromise research participant privacy. The transcripts can be obtained upon reasonable request from the authors (kjacob@kemri-wellcome.org).

\section{Extended data}

Harvard Dataverse: Kenya's Strategic Health Purchasing Progress Matrix and notes from the stakeholder engagement workshop https://doi.org/10.7910/DVN/KPXCXL ${ }^{18}$.

This project contains the following extended data:

- Strategic health purchasing progress matrix

- Notes from stakeholder engagement workshop

- Interview guide for key informant interviews

Data are available under the terms of the Creative Commons Attribution 4.0 International license (CC-BY 4.0).

\section{Author contributions}

EB and KM conceptualised the study. JK and EK collected data and performed preliminary analysis. JK developed the first draft. All authors contributed to subsequent and final drafts as well as further analysis.

\section{Acknowledgements}

This manuscript is published with the permission of the Director of KEMRI. For the purpose of Open Access, the author has applied a CC-BY public copyright licence to any author accepted manuscript version arising from this submission. 
1. UNITED NATIONS: The sustainable development goals report. United Nations New York. 2016.

Reference Source

2. World Health Organization: WORLD HEALH REPORT (The): Health Systems Financing: the path to universal Coverage (Arabic). World Health Organization. 2010.

Reference Source

3. O'Connell T, Rasanathan $\mathrm{K}$, Chopra M: What does universal health coverage mean? Lancet. 2014; 383(9913): 277-279.

PubMed Abstract | Publisher Full Text

4. Kim JY: THE GLOBAL PUSH FOR UNIVERSAL HEALTH COVERAGE. World Bank Group, 2014; (accessed 10/26/2018, 12: 05).

Reference Source

5. HEFREP: The NHIF we want - Report of the Health Financing Reforms Expert Panel for the transformation and repositioning of National Hospital Insurance Fund as a strategic purchaser of health servises for the attainment of Universal Health Coverage by 2022. 2019. Reference Source

6. McIntyre D: Learning from experience: health care financing in low- and middle-income countries. Global forum for health research Geneva. 2007. Reference Source

7. Mathauer I, Dale $E$, Jowett $M$, et al.: Purchasing health services for universal health coverage: How to make it more strategic? World Health Organization. 2019.

Reference Source

8. Honda A: What is strategic purchasing for health? 2014 Publisher Full Text

9. Mbau R, Kabia $E$, Honda $A$, et al.: Examining purchasing reforms towards universal health coverage by the National Hospital Insurance Fund in Kenya. Int J Equity Health. 2020; 19(1): 19 PubMed Abstract | Publisher Full Text | Free Full Text

10. Hope KR: Devolved government and local governance in Kenya: Implementing decentralization underpinned by the 2010 constitution. $A f r$ Asian Stud. 2014; 13(3): 338-358. Publisher Full Text

11. LAWS OF KENYA: The Constitution of Kenya: 2010. 2013: Chief Registrar of the Judiciary. Reference Source

12. Barasa $E$, Nguhiu $P$, McIntyre $D$ : Measuring progress towards sustainable development goal 3.8 on universal health coverage in Kenya. BMJ Glob Health. 2018; 3(3): e000904.

PubMed Abstract | Publisher Full Text | Free Full Text

13. Barasa EW, Maina T, Ravishankar N: Assessing the impoverishing effects, and factors associated with the incidence of catastrophic health care payments in Kenya. Int J Equity Health. 2017; 16(1): 31 PubMed Abstract | Publisher Full Text | Free Full Text

14. Mulaki A, Muchiria S: Kenya Health System Assessment. Washington DC 2019.

Reference Source

15. Ministry of Health: Kenya National Health Accounts FY 2015/2016: The 2019 update. 2019 Reference Source

16. Ministry of Health: KENYA HOUSEHOLD HEALTH EXPENDITURE AND UTILIZATION SURVEY, 2018. 2018.

17. Tong A, Sainsbury $P, C$ raig J: Consolidated criteria for reporting qualitative research (COREQ): a 32-item checklist for interviews and focus groups. Int Qual Health Care. 2007; 19(6): 349-357. PubMed Abstract | Publisher Full Text

18. Kazungu J, Kabia E, Munge $K$, et al.: Kenya's Strategic Health Purchasing Progress Matrix. Harvard Dataverse, V3. 2021 http://www.doi.org/10.7910/DVN/KPXCXL

19. World Health Organization: The health financing progress matrix: country assessment guide. 2020 . Reference Source

20. Kazungu J, Kabia E, Munge K, et al.: Kenya's Strategic Health Purchasing Progress Matrix. Harvard Dataverse. 2021. Publisher Full Text

21. Cashin C, Nakhimovsky S, Laird K, et al.: Strategic Health Purchasing Progress: A Framework for Policymakers and Practitioners. 2018. Reference Source

22. World Health Organization: Health Financing Progress Matrix: real-time assessment of country health financing policy in support of UHC. Health financing guidance.

Reference Source

23. Gale NK, Heath G, Cameron $\mathrm{E}$, et al.: Using the framework method for the analysis of qualitative data in multi-disciplinary health research. BMC Med Res Methodol. 2013; 13(1): 117.

PubMed Abstract | Publisher Full Text | Free Full Text

24. Srivastava A, Thomson SB: Framework analysis: a qualitative methodology for applied policy research. 2009.

Reference Source

25. Ritchie J, Spencer L: Qualitative data analysis for applied policy research The qualitative researcher's companion. 2002; 573(2002): 305-29. Publisher Full Text

26. Ministry of Health: REPORT ON THE UHC - ESSENTIAL BENEFITS PACKAGE.

27. Ministry of Health: Kenya Essential Medicine List - 2019. 2019. Reference Source

28. Obadha M, Chuma J, Kazungu J, et al.: Health care purchasing in Kenya: Experiences of health care providers with capitation and fee-for-service provider payment mechanisms. Int J Health Plann Manage. 2019; 34(1): e917-e933.

PubMed Abstract | Publisher Full Text | Free Full Text

29. National Hospital Insurance Fund Act No. 9 of 1998. 2012.

30. Torres FM, Baeza C: From Whom to Buy? Selecting Providers. Spending Wisely: 79

31. van den Broek-Altenburg EM, Atherly AJ: The relation between selective contracting and healthcare expenditures in private health insurance plans in the United States. Health Policy. 2020; 124(2): 174-182. PubMed Abstract | Publisher Full Text

32. Zwanziger J, Melnick GA, Bamezai A: The effect of selective contracting on hospital costs and revenues. Health Serv Res. 2000; 35(4): 849-67. PubMed Abstract | Free Full Text

33. Mbau R, Kabia E, Barasa $E$, et al.: Examining multiple funding flows to public healthcare facilities in Kenya. 2018 Reference Source

34. Onwujekwe O, Mbachu C, Ezenwaka U, et al:: Characteristics and Effects of Multiple and Mixed Funding Flows to Public Healthcare Facilities on Financing Outcomes: A Case Study From Nigeria. Front Public Health. 2020; 7 403. PubMed Abstract | Publisher Full Text | Free Full Text

35. Cashin C, Ankhbayar B, Phuong H: Assessing health provider payment systems: a practical guide for countries working toward universal health coverage. Washington, DC: Joint Learning Network for Universal Health Coverage, 2015.

Reference Source

36. Gosden T, Forland F, Kristiansen IS, et al.: Capitation, salary, fee-for-service and mixed systems of payment: effects on the behaviour of primary care physicians. Cochrane Database Syst Rev. 2000; 2000(3): CD002215. PubMed Abstract | Publisher Full Text

37. Langenbrunner JC, Cashin C, O'Duagherty S: Designing and Implementing Health Care Provider Payment Systems : How-to Manuals. The World Bank 2009. Reference Source

38. Clarke D: Law regulation and strategizing for health. Strategizing national health in the 21 st century: a handbook. Geneva: World Health Organization, 2016. Reference Source

39. Figueras J, Robinson R, Jakubowski E: Purchasing to improve health systems performance. McGraw-Hill Education (UK). 2005. Reference Source

40. National Academy of Engineering (US) and Institute of Medicine (US) Committee on Engineering and the Health Care System: Reid PP, Compton WD, et al.: Information and communications systems: The backbone of the health care delivery system. In Building a Better Delivery System: A New Engineering/Health Care Partnership. National Academies Press (US). 2005. Reference Source

41. Selçuk AA: A guide for systematic reviews: PRISMA. Turk Arch Otorhinolaryngol. 2019; 57(1): 57-58.

PubMed Abstract | Publisher Full Text | Free Full Text

42. Kazungu JS, Barasa EW: Examining levels, distribution and correlates of health insurance coverage in Kenya. Trop Med Int Health. 2017; 22(9): 1175-1185.

PubMed Abstract | Publisher Full Text | Free Full Text 


\title{
Open Peer Review
}

\section{Current Peer Review Status:}

\section{Version 1}

Reviewer Report 27 April 2021

https://doi.org/10.21956/wellcomeopenres.18304.r43482

(C) 2021 Kwesiga B. This is an open access peer review report distributed under the terms of the Creative Commons Attribution License, which permits unrestricted use, distribution, and reproduction in any medium, provided the original work is properly cited.

\section{Brendan Kwesiga}

Health Systems Cluster, World Health Organization, Nairobi, Kenya

\section{Assessing the progress and gaps in strategic health purchasing in Kenya}

I would recommend that you change the title to show that is specific to purchasing of health care services based on the content included in the article (i.e. "Assessing the progress and gaps in purchasing of health care services in Kenya").

\begin{abstract}
In the results section, there is need for consistency in numbering for both the progress and bottlenecks identified.

Conclusion provided is very generic (i.e. "there is a need to implement reforms that will align the purchasers' actions and decisions to the ideals of strategic health purchasing"). Reforms in what specific areas? Maybe aspects for which progress was limited.
\end{abstract}

\section{Introduction}

In describing public sector purchasing in Kenya, you mention the health system context of devolution in Kenya and how it is likely to affects success/failure of strategic purchasing initiatives for the purchasing arrangements presented.

It would also be important as part of the background to mention the percentage composition of the different resource pools used for purchasing. This is an important component of the background because while it is important to be strategic with $20 \%$ of our resources, it would be even more important if we achieve this with $80 \%$ of the resources. This should emphasize the need for ensuring strategic purchasing with government resources.

No need to mention the provider payment mechanisms used by the purchasers in this section as it should be part of your results.

\section{Methods}

I suggest that the study setting focuses on describing how the health system is organized. The health financing context specific to strategic health care purchasing should be moved to the background/introduction as recommended above. 


\section{Results}

I recommend that all components of the conceptual framework are reported on and not specific components as is the current results section even within the framework of "what to buy, from whom, and how". This makes it difficult to link the methods and results section. Please present the results as per the purchasing functions in the conceptual framework. From these functions, you could then capture the important components based on the findings.

\section{Discussion}

From reading the discussion section, I feel that most of the sections are a repetition of the results section (i.e. stating of "what should be" (conceptually) and "what is"). I suggest that statement of results should be at most one to two paragraphs (i.e. "this is what we found"). The comparison with the previous studies could then be done separately.

Based on the identified limitations, you could suggest areas for further studies.

Is the work clearly and accurately presented and does it cite the current literature? Yes

Is the study design appropriate and is the work technically sound?

Yes

Are sufficient details of methods and analysis provided to allow replication by others? Yes

If applicable, is the statistical analysis and its interpretation appropriate? Not applicable

Are all the source data underlying the results available to ensure full reproducibility? Yes

Are the conclusions drawn adequately supported by the results? Partly

Competing Interests: No competing interests were disclosed.

Reviewer Expertise: Health Economics, Health Financing, Health Systems Strengthening.

I confirm that I have read this submission and believe that I have an appropriate level of expertise to confirm that it is of an acceptable scientific standard, however I have significant reservations, as outlined above. 